\title{
An integrated supply chain - human resource management approach for improved supply chain performance
}

\author{
Jena, S. K. and Ghadge, A.
}

\begin{abstract}
Purpose: Human resource management is struggling to cope with the increasingly volatile demand for skilled resources in the logistics and supply chain sector. Thus, this study discovers the possible integration of human resource management (HRM) and supply chain management (SCM) practices for improved supply chain performance. The purpose of the study is to explore the effect of intra HRM-SCM and joint HRM-SCM decisions on the performance of the supply chain.
\end{abstract}

Design/methodology/approach: An intra HRM-SCM and joint HRM-SCM management model is developed following an empirical study. Survey data collected from 109 supply chain managers from Indian logistics firms are used to test the developed hypotheses. Structural equation modelling is used to analyse and validate the model.

Findings: The results suggest that supply chain performance is significantly influenced by joint HRM-SCM, compared to intra HRM-SCM practices, especially under volatile demand environments. Training and development, recruitment and selection, and performance management affect joint HRM-SCM significantly compared to the other three factors identified. Moreover, HRM and SCM show strong correlation and mutual support in identifying and fulfilling the demand of the logistics and supply chain sector.

Practical implications: With a growing trend towards globalization and digitalization, a joint HRM-SCM model will help businesses make robust and informed decisions for improved supply chain performance.

Originality/value: An empirical relationship between joint HRM-SCM, intra HRM-SCM, supply chain inhibitors, and supply chain performance is established in this study. Although some part of this relationship may already exist, the study provides robust evidence to support this complex, collaborative relationship.

Keywords: Supply chain performance, Supply chain integration, Human resource management, Supply chain inhibitors, Logistics competencies

\section{Introduction}


Logistics, a part of supply chain management (SCM) is used to maximize customer value and achieve sustainable competitive advantage through effective movement and storage of related goods and information from origin to destination (Gopal and Thakkar, 2016). The global logistics industry is constantly growing due to an increase in online transactions (Maiden, 2020). Moreover, the growing demand for logistics services in India is largely driven by the remarkable growth of the Indian economy (Gopal and Thakker, 2016; Tiwari and Kalogerakis, 2017). This growth is projected to be around 9-10 percent over the next few years, with the compounded annual growth rate expected to grow at 7-8 percent (LCLogistics, 2011; Gopal and Thakker, 2016). Currently, the logistics sector contributes more than 7 percent to India's GDP (Gupta et al., 2018). Globalization, dynamic environment, technological innovation, and the increasing role of the logistics firms' strategic planning intensify the need for skilled supply chain experts who can manage the supply chain's multiple activities effectively through statistical analysis and engage in fact-based decision making (Ellinger and Ellinger, 2014). Moreover, Indian logistics firms are faced with a shortage of talented supply chain experts, leading to operational inefficiency on several fronts (Li \& Fung limited 2012; Bureau, 2020). Although the remuneration paid to supply chain managers is steadily rising, supply chains face a serious sector-specific skill shortage, and this gap is expected to worsen over the coming years (Ding et al., 2015).

The shortage of Logistics and SCM managers with an extensive set of skills to satisfy market demand can be largely attributed to many firms placing more emphasis on the cost reduction and customization process than on developing people's skills to achieve SCM objectives (Prajogo and Sohal, 2013; Ellinger and Ellinger, 2014). Relative lack of focus on the people's skills in SCM may create barriers to developing operational innovation. This happens due to a lack of interest and knowledge of logistics and SC managers towards operational innovations (Hammer 2004, p. 84). However, nowadays, logistics firms are focused on developing the skill sets and knowledge required for innovative working environments within and between the firms (Mentzer et al., 2008).

The shortage of SCM expertise is further compounded by a lack of resources and strategically focused organizations where senior-level managers tend to have limited knowledge of SCM (Hammer, 2004; Slone et al., 2007), which thereby creates a negative influence on supply chain performance (SCP). Besides, supply chain managers also need a balanced knowledge of hard (analytical and technical) and soft (human and behavioral) skills to accomplish seamless integration in the current global and competitive business environment (Sweeney, 2013). Furthermore, supply chain managers must be capable of multi-tasking and 
have analytical proficiency for coordination with different network partners. However, recent prescriptions for achieving better coordination contend that acquiring and developing the best SCM talent is the first phase of execution of the supply chain transformation strategy (Dittmann, 2012; Slone et al., 2010). Further, to minimize the talent shortfall, logistics experts suggest that SCM managers must go through training and development processes for acquiring the necessary skills and gain competitive competencies to manage increasingly complex and dynamic supply chain processes (Barnes and Liao, 2012; Prajogo and Sohal, 2013). While conducting and providing such training sessions, the coordination between Human Resource Management (HRM) and SCM experts is important for achieving effective SCP (Ellinger and Ellinger, 2014).

Recent SCM research has used a knowledge-based view (KBV) as a theoretical basis for the alignment of expertise between SCM and HRM (Flothmann et al., 2018). This theoretical lens views knowledge as a company's most strategically important resource and investigates the impact of knowledge on supply chain and/or firm performance (Flothmann et al., 2018). Meanwhile, HRM plays a vital role in identifying the resources with the appropriate skills needed for improving SCP (Guersola et al., 2018). Numerous studies have argued that, to obtain better SCP, the next trend of HRM should focus on the people and skills necessary to manage and operate increasingly complex supply chains (e.g., Daugherty et al., 2000; Agyabeng-Mensah et al., 2020). Therefore, HRM practices increase competitive advantage by leveraging external customers and supply resources (Koulikoff-Souviron and Harrison, 2010). Furthermore, HRM practices have emerged as one of the important strategic priorities in supply chain and firms' efforts to gain sustainable growth by leveraging human capital (Stank et al., 2011; Hohenstein et al., 2014; Huo et al., 2015). The professionals' capabilities in training and development and change management help supply chain managers disseminate a broader understanding of SCM concepts within and between firms (Ellinger and Ellinger, 2014).

The SCM literature often focuses on managing supplier and customer relationships, ignoring the essentials of HRM activities such as recruitment, succession planning and training in Logistics and SCM (Sweeney, 2013; Hohenstein et al., 2014). Thus, human resource management practices have not adequately advanced to understand the needs of SCM, resulting in a severe shortage of skilled resources in logistics and SCM (LCLogistics, India, 2011). Recently, Flothmann et al. (2018), examining the relationship between SCM and HRM, have also identified the effect of HRM through knowledge and employee development on supply chain performance. Employee performance is improved through the set of HRM practices (Ahmad and Schroeder, 2003). Moreover, intensified competition at the supply chain level, 
complex business environment, and increasingly volatile market have encouraged most firms to increase their attention towards closer integration between HRM and SCM (Gmelin and Seuring, 2014). Thus, investigating the integration of HRM and SCM practices and determining their roles on SCP is necessary, as it should enable supply chain managers to better leverage human capital and skills.

Different practices of HRM at the intra-/inter-level of organizations have brought much attention to SCM since the logistics process within a supply chain is human-centric (Hohenstein et al., 2014). In addition, most SCM relationships occur at the intra- or inter(joint)organizational level (Koulikoff-Souviron and Harrison, 2010). Therefore, at an intra HRMSCM level, each logistics/automotive firm implements HRM practices for sharing different skills and knowledge among its supply chain managers (Giunipero et al., 2006), whereas, at a joint HRM-SCM level, each logistics/automotive firm shares the HRM and SCM practices among themselves for mitigating the shortfall of professionals (Swart et al., 2012; Ellinger and Ellinger, 2014). This joint effort, based on trust, experience, skill, information-sharing practices, and fair treatment, could contribute to highly entrepreneurial, cross-industry, network organizations. However, Fisher et al. (2010), Lengnick-Hall et al. (2013), and Ding et al. (2015) highlight that intra HRM-SCM (IHRM-SCM) and joint HRM-SCM (JHRM-SCM) practices is a neglected area of research in the supply chain literature.

In addition, the effect of IHRM-SCM and JHRM-SCM practices on the SCP also remains unexplored in the existing literature (Guinipero et al., 2006 Pandey et al., 2012; Ding et al., 2015), and research advises that HRM interventions in SCM contexts are associated with beneficial outcomes. For example, in SCM settings, the interpersonal implications of conventional transaction-based approaches to SCM personnel are contrasted with the possible advantages of adopting relationship-based human resource techniques (McAfee et al., 2002; Shub and Stonebraker, 2009; Ellinger and Ellinger, 2014). Moreover, earlier studies have claimed that supply chain experts and supply chain researchers face significant challenges to understand the relationalities between HRM and SCM practices and their influence on SCP (Farndale et al., 2010; D'Aleo and Sergi, 2017). This multi-faceted perspective has also been unmistakably lacking in the Indian context (Charan et al., 2008; Ganga and Carpinetti, 2011). For example, Joshi et al. (2013), investigating drivers for SCP in the Indian automotive industry, fail to consider the integration of HRM and SCM on SCP considering SCM experts. These evident research gaps motivate us to understand the SCM and HRM experts' perceptions concerning the impact of the integration of SCM and HRM practices on SCP from an Indian 
logistics industry perspective. The current research is also expected to provide better visibility in managing future skill shortages in the Indian logistics industry.

Fisher et al. (2010) mention that the objective of integrating SCM and HRM is to build long-term relationships between different stakeholders for improving SCP. According to Fisher et al. (2010), intra HRM-SCM and joint HRM-SCM can be measured by six practices: Skill and Knowledge (SKA), Recruitment and Selection (R\&S), Training and Development (T\&D), Performance Management (PM), Reward Management (RM), and Change Management (CM). These HRM practices are used for improving the firm's supply chain performance (LengickHall et al., 2013; Hohenstein et al., 2014). However, the literature suggests that SCP is fundamentally affected by supply chain inhibitors (SCI) (Gopal and Thakker, 2016). Inhibitors are factors that prevent the achievement of operational performance (Bayraktar et al., 2009) and, thus, lead to a negative impact on SCP (Power, 2005). Therefore, it is very important to understand the effect of intra HRM-SCM (IHRM-SCM) and joint HRM-SCM (JHRM-SCM) practices on SCP in the presence of SCI. Here, the study explores the relationships among the JHRM-SCM, IHSRM-SCM, SCI and SCP, as shown in Figure 1.

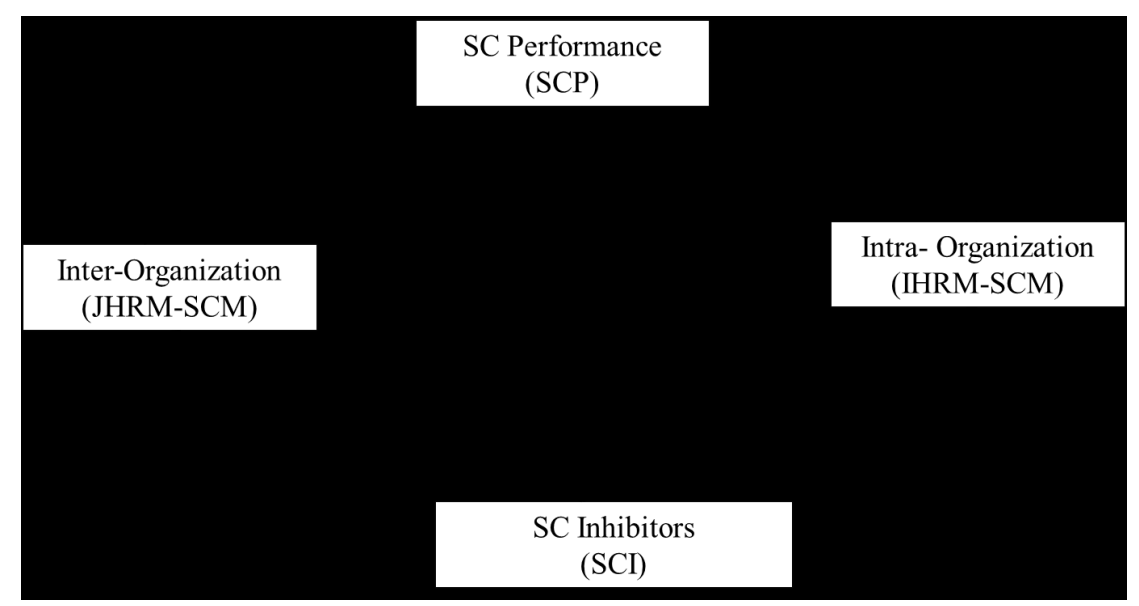

Figure 1. Proposed conceptual model

From both a theoretical and practical perspective, addressing these multi-faceted relational issues is important. Based on the firm's knowledge-based view (Grant, 1996), this paper suggests both internal and external expertise and skills and transfer of competencies to positively influence the efficiency of the supply chain. Internal knowledge transfer is defined as the capacity of a firm to share HRM activities with SCM practices internally (Tsai, 2001). External knowledge transfer is characterized as the ability of the firm to leverage the knowledge of external managers to support the processes of the business (Blome et al., 2014). 
Although studies have shown the value of knowledge, skills, and competence, there is a need for further study in relation to performance in the supply chain (Craighead et al., 2009). From this theoretical standpoint, it is easy to see how companies investing in joint HRM and SCM activities will improve their SCP. However, this is not empirically proven. Thus, the study aims to conduct an empirical investigation into the effect of intra HRM-SCM and joint HRM-SCM practices on supply chain performance.

This paper is organized as follows. We present a literature review to support the research framework and hypothesis in Section 2; the research methodology describes the data collection procedures and sample profile in Section 3; Section 4 focuses on the analysis of data. Implications of the study are discussed in Section 5. The concluding section presents the findings, contribution, and future research avenues.

\section{Literature review and hypothesis development}

Following a knowledge-based view (KBV), firms can establish a strategic relationship between HRM and SCM if their strategies are aligned (Barney, 1991; Grant, 1996; Flöthmann et al., 2018). The relevant literature is reported under two sub-sections, i.e., (1) JHRM-SCM and IHRM-SCM on SCP and (2) SCI on SCP and integration of HRM-SCM. The study developed a set of five hypotheses following a critical literature review to understand the effect of various indicators of IHRM-SCM, JHRM-SCM on SCP. Appendix A illustrates the detailed description of all constructs along with the measurement indicators.

\subsection{JHRM-SCM and IHRM-SCM on SCP}

The idea of leveraging human capital strategically for the benefit of SCM is not new. Because human experiences primarily influence SCM operation, the approach for human resource growth has a direct effect on the performance of the supply chain (McAfee et al., 2002; Rogowski et al., 2005; Sweeney, 2013). For example, Gowen and Tallon (2003) suggest that HRM can positively influence SCP. However, supply chain performance measures various factors such as on-time delivery (OD), market share (MS), return on investment (ROI), and total inventory cost (TIC). These measures are adopted by Gunasekaran et al. (2004), Fawcett et al. (2008) and Gopal and Thakkar (2015). Appendix A provides a list of measurement indicators identified from the literature. Swanson and Holton (2009) discuss that HRM professionals are responsible for designing and implementing training and development initiatives that improve supply chain performance. The integration of HRM in the SCM is now 
identified as a primary strategy for improving SCP (Othman and Ghani, 2008; Stank et al., 2011).

Sweeney (2013) discusses the impact of HRM on supply chain integration and their relationships. However, largely, the supply chain network perspective is found to be lacking. Therefore, researchers are working towards understanding how Human Resources (HR) can be best managed to maximize productivity and enhance creativity while controlling costs, thereby improving organizational performance (Cao and Zhang, 2011; Kaliani Sundram et al., 2016).

Few researchers have observed that human resource factors could improve the effectiveness of SCM practices (e.g., Gowen et al., 2006; Ellinger et al., 2011; Ding et al., 2015). However, attaining these capabilities requires employees to be flexible in their roles, have a broad set of skills, adapt to reorganization, and work in boundary-spanning responsibilities (Othman and Ghani, 2008). Drawing upon these studies, our study aims to advance knowledge on the HRM and SCM interface by empirically investigating the effect of HRM practices on SCP.

\subsection{SCI on SCP, JHRM-SCM, and IHRM-SCM}

SCP is measured based on the capability to fulfil customers' requirements in the form of both cost and quality (Ho et al., 2002; Chen and Paulraj, 2004). However, understanding the effect of the integration of HRM and SCM on SCP will not be complete unless due consideration is provided to supply chain-related inhibitors (Govindan and Hasanagic, 2018 Zhang and Cao, 2018). Meanwhile, past literature discusses measures and establishes the need for SC performance considering SCI (Gunasekaran et al., 2004; Liu et al., 2018). Supply chain inhibitors comprise elements that avert the improvement of SCP. The primary reason for considering specific inhibitors is to make the supply chain transparent (Faisal, 2015). Thus, it is very important to know how supply chain inhibitors influence SCP during joint HRM-SCM implementation and intra HRM-SCM implementation. As a result, it will help the supply chain manager to identify and proactively eliminate the impact of supply chain inhibitors during joint HRM-SCM implementation. Fawcett et al. (2008) address that inhibitors to supply chain management arise both from the nature of the organization and human resources that constitute the organization. Furthermore, inhibitors can be considered from the angle of inter-firm rivalry and managerial complexity (Tatoglu et al., 2016). A set of SCM inhibitors are recognized in the Indian logistics and automobile business setting based on past work undertaken by Luthra et al. (2011) and Gopal and Thakkar (2016). Challenges such as market size, the absence of government support, technology adoption, lack of communication, and a shortage of supply 
chain professionals, will play a negative role in SCP (Gopal and Thakker, 2016). These inhibitors comprise culture (CL), cost implications (CI), supplier reluctance (SR), shortage of skilled professionals (SSP), lack of commitment from top management (LTC), market characteristics (MC), and industry competition (Comp).

\subsection{Hypothesis development}

Multiple studies (e.g., Ding et al., 2015; Gupta et al., 2018; Gopal and Thakker, 2018) have identified the integration of SCM and HRM practices as one of the biggest challenges in India, especially in the logistics industry. The effect of HRM practices on SCM and its association with performance have been explicitly investigated by Ding et al. (2015) in a representative sample of Chinese L\&SC enterprises ( $n=126)$. However, they have not considered the joint HRM-SCM and intra HRM-SCM practices on SCP. Moreover, joint HRM-SCM and intra HRM-SCM are measured by six HR indicators adopted from Fisher et al. (2010): Skill and Knowledge (SKA), Recruitment and Selection (R\&S), Training and Development (T\&D), Performance Management (PM), Reward Management (RM), and Change Management (CM).

Kam et al. (2010) and Lieb (2008) identify recruitment and selection as one of the biggest challenges in the Chinese logistics industry. Fong et al. (2011) identify that recruitment and selection practices have a significant positive association with knowledge sharing, which can lead to improved supply chain capability. At the same time, Murphy and Poist (2006) and $\mathrm{Wu}$ et al. (2013) observe that knowledge sharing can lead to improved supply chain performance between logistics firms.

Performance management activities include monitoring the progress, looking into training and development, and deciding rewards and disciplinary actions (Cakar et al., 2003). Bendickson and Chandler (2019) address that training and development can serve as a resource that enhances supply chain performance. Ketchen and Hult (2007) argue that skill and trust are necessary for the better performance of SC networks. In the intra HRM-SCM case, logistics firms develop job-related performance appraisal systems and align each firms' SCP levels. Meanwhile, in the joint HRM-SCM case, any firm can provide feedback on other firms' individual and group performance (Fisher et al., 2010). Here, all the firms are aligned together to form a common reward dimension across the supply chain network.

Reward refers to merit pay or compensation by the firms to the employees for achieving specific goals (Delaney and Huselid, 1996). In intra HRM-SCM, a pay system is developed to attract, motivate, and retain SC professionals for a specific goal; whereas, in joint HRM-SCM, firms form an aligned or common pay incentive system for workers across the SC network. 
Typically, in SC, to attract and retain skilled employees, managers use intrinsic and extrinsic reward systems to improve the SCP. Intrinsic rewards are in the form of work security, empowerment, and participation; meanwhile, extrinsic rewards include pay, working conditions, and housing benefits (Ding et al., 2015). Ellinger et al. (2005) observe that compensation for work is an essential predictor of work performance, even though computation and its competitive distribution is limited for SCM. However, Fisher et al. (2010) and Ellinger et al. (2014) observe that the rewards management process has a significant positive association with change management, leading to improved supply chain performance between logistics firms.

Change management is a systematic approach to introducing new systems and programs for organizations. In intra HRM-SCM, the manager introduces a new system within the firm by using models of planned change (Fisher et al., 2010); however, in joint HRM-SCM, the firm introduces new chain relationships among employees by introducing models. Organizational change cannot be separated from HRM strategy (Burnes, 2004), and these organizational changes must be efficiently dealt with by skilled employees. In addition, theoretical support for our argument regarding the positive influence of expertise, skills, and competence transfer on supply chain efficiency by intra HRM-SCM and joint HRM-SCM is given through the firm's knowledge-based view. Within this context, information is a valuable resource capable of assisting firm efficiency. Thus, by understanding intra HRM-SCM and joint HRM-SCM methods, companies can develop SCP in a sustainable manner (GómezCedeño et al., 2015; Zaid et al., 2018).

To sum up, the literature supports synergies between the different practices, and we would expect SCM and HRM practices to coexist, at least in the long run. It is reasonable, then, to expect a significant correlation between the different HRM-SCM practices on SCP. Thus, we develop the following hypotheses:

H1: Adoption of intra HRM -SCM has a positive effect on SCP.

H2a: Adoption of joint HRM-SCM has a positive effect on SCP.

The existing literature also observes that human resource management practices may significantly impact logistics and supply chain operations. Thus, we develop another hypothesis as follows:

\section{H2b: Joint HRM-SCM has a stronger effect on SCP.}

Here, SCI activities are considered to be barriers for SCM, which indicates a lack of trust in the relationship between SCM and HRM practices (Hassini et al., 2012). Likewise, poor 
implementation of these HRM practices in SC can negatively influence employees' job satisfaction and organizational performance (Chand and Katou, 2007). HRM professionals can outline the organizational culture of individual organizations by their change management efforts (Fisher et al., 2010). While doing this, it is essential to understand the influence of culture on external and internal SCP. Another key inhibitor is the firm's flexibility: the firm's ability to transfer from an inter to intra-supply chain system based on requirements. Understanding the association of a firm's human capital with organizational flexibility and its competitive advantage is also important.

The above argument proposes that the HRM and SCM challenge negatively affects SCP, intra HRM-SCM and joint HRM-SCM (Saad et al., 2006; Huo et al., 2015). Although these relationships have not been empirically tested in previous research, these challenges are likely to be the core reasons preventing the performance of logistics services in their supply chain networks. This leads to the following hypotheses.

\section{H3: Supply chain inhibitors have a negative effect on intra HRM-SCM competency. \\ H4: Supply chain inhibitors have a negative effect on joint HRM-SCM competency. \\ H5: Supply chain inhibitors negatively influence SCP.}

\section{Research methodology}

To test our hypotheses, a multi-respondent survey was used to gain insights from respondents who understand HRM and SCM practices and their potential impact on supply chain performance. This method avoids biases due to single respondents. We developed two questionnaires: one for senior HR managers and another for senior supply chain managers. Having two different sets of questionnaires enabled the distinct analysis of the relationship between HRM and SCM practices and their impact on supply chain performance. Since hypotheses were developed from the proposed conceptual model (Figure 1), the questionnaire used measurement indicators of HRM practices, supply chain inhibitors, and supply chain performance (refer to Appendix A) to explore their intra and joint HRM-SCM link. These measurement variables were identified from the extant literature.

This research design allowed to obtain measures of predictor and criterion variables from different sources, which helped control method bias (Podsakoff et al., 2012). Several other researchers have previously proposed similar techniques (e.g., Guerci et al., 2016; Zaid et al., 2018; Wang et al., 2018; Kumar et al., 2019) to identify the data needed to test suggested hypotheses. 
We conducted a primary survey of a combined 122 SCM and HRM experts on ten HRM-SCM practices that are employed in the Indian logistics sector (LCLogistics 2011; Joshi et al. 2013; Gopal and Thakker, 2016). Of the ten management practices, $S K A, R \& S, T \& D$, $P M, R M$, and $C M$ are part of HRM practices. The first four are central to the human resource manager-supply chain manager relationship. These four practices are necessary for knowledge up-gradation and delivery of desired standards at a minimum cost. The last two add the incentive mechanisms to motivate people to participate in the continuous improvement process. The SCM practices comprise on-time delivery, market share, return on investment, and total inventory cost.

\subsection{Construct operationalization and content of scale items}

A set of items from pre-validated measurements were employed to develop the one-dependent variable (i.e., SCP and this dependent variable defined in four factors such as on-time delivery, market share, return on investment, and total inventory cost) and two independent variables (i.e., intra HRM-SCM and joint HRM-SCM and these two independent variables can be defined in the six factors of $S K A, R \& S, T \& D, P M, R M$, and $C M$ ) and one control variable (SCI, and defined in terms of $C L, C I, S R, S S P, L T C, M C$, and Comp). Appendix A presents the measurement indicators of all the constructs used in the study. Here, we have considered a set of constructs shown in Figure 1 and these are measured by the number of observed variables, called measurement indicators.

The content validity of these items was evaluated in three ways to certify the high level of correspondence between items and constructs. First, most of the items in the study are taken from existing scales that have already been checked for content validity (Choi et al., 2008; Wang et al., 2008; Warner, 2008; Fisher et al., 2010; Ding et al., 2014; Huo et al., 2015; Gopal and Thakkar, 2015). Second, the investigators examined all the items to ensure that they cover the main domain of the constructs. Third, industry experts and several academics confirmed the acceptability of the items in the pilot test stage.

\subsection{Questionnaire development}

A self-administered questionnaire survey has been used as the instrument for data collection. Considering the potential low response rate, the questions were designed to be simple, straightforward, and easy to understand to cover the construction to be explored (Fowler, 1993). The questionnaire was pretested through discussions with academicians and supply chain managers, and two human resource managers to ensure content validity. 
The questionnaire consisted of two main sections. Section one sought general information on firms' characteristics. Section two contained items measuring the integration of HRM and SCM factors adopted in India by the logistics and automotive sectors. The questionnaire was made in English to ensure understandability. Section one comprised the questions related to general information on the firm's characteristics. In section two, a sevenpoint Likert scale (1-strongly disagree to 7-strongly agree) was adopted to measure the perceptions of respondents. Several research studies (e.g., Zhou and Benton, 2007; Huo et al., 2016) use similar Likert scales, which is found to be suitable for this study.

\subsection{Sampling and data collection}

The economic and SC performance issues of the logistics and automotive industry are significant (Mitra and Datta, 2014). We found a list of potential contacts for this research through an Indian industry network comprising the Automotive Components Manufacturers Association (ACMA) of India, National Highways Authority (NHA) of India, and Confederation of Indian Industry (CII). A survey instrument was developed to investigate the hypotheses. The employee size of $90 \%$ of the selected firms was around 200-1000. The final questionnaire was circulated to managers, senior managers and senior executives of the selected firms.

The same set of questionnaires was sent to both HR and SC managers or senior executives to reduce bias. Here, we wanted to understand the perception of HR and SC managers concerning the effect of a joint HRM-SCM strategy on SCP. If SC/HR senior managers/senior executives were not confident of their knowledge concerning the questions asked, they were able to nominate the staff member most conversant with the information requested, as per the process used by Kaufmann and Carter (2006). Of the 1043 email invitations sent out, 425 were returned with an invalid or non-existent email address. The questionnaire was posted to 815 valid email addresses following a web survey and offline mode. In the offline mode, respondents were visited in person (around 10\%) for filling the questionnaire survey. Meanwhile, in the online web survey mode, the questionnaire link was emailed to the respective respondents (around 740) to collect their replies. To enhance the response rate, four waves of weekly reminder emails were sent to reduce the response bias due to the use of single information.

A total of 122 responses were obtained from the survey with a response rate of $14.96 \%$, from which 13 responses were eliminated due to incompleteness. The final sample size of 109 , representing a usable reaction rate of around 13\%, was used for the study. Freight forwarding, 
transportation, warehousing, and distribution were the four major logistics services considered for this study. The detail of sample analysis is provided in Appendix B.

\section{Data analysis}

The authors checked the non-response bias by comparing early and late responses to reveal significant differences, if any (Armstrong and Overton, 1997; Blome et al., 2014). Here, a total of 109 responses were divided into two groups based on their time of return and a $t$-test was performed on them (Ding et al., 2015). The results of the two samples revealed no statistically significant difference $(t=14.115, p>0.05)$ for all three categories (logistics experience, company size, and knowledge of integration of HRM with SCM). The difference between the two groups for the categories was at the 5\% level. Thus, the sample was not found to have a response bias and was used for the next level of analysis. The mean and standard deviation (SD) values for each of the indicators indicate those respondents who have deputed high importance to high mean value factors, as shown in Table 1. The normality test was conducted independently through a box plot and multivariate normality test for all constructs. Based on the results, it was found that the data were normally distributed. Common method bias (CMB) was tested through Harman's single factor test (Doty and Glick, 1998; Podsakoff et al., 2003). The average variance of the single factor was found to be $32.74 \%$, which is less than $50 \%$. Based on these results, it was observed that the data were not threatened by CMB.

A three-step methodology for analysing the data was introduced to define the relationship between the indicators on SCP. In the first step, Exploratory Factor Analysis (EFA) was conducted to discover the three most significant indicators (joint HRM-SCM, intra HRMSCM and SCI) from the factors listed and to discern whether specific indicators fully explained the constructs. Confirmatory Factor Analysis (CFA) was focused on the second step to quantify the convergent and discriminant validity. In the third step, the structural model was developed to analyse the concept and test the hypothesis.

\subsection{Factor analysis: $\mathrm{EFA}$}

The suitability of data for EFA was established by performing Bartlett's sphericity test; KaiserMeyer-Olkin (KMO) was followed to check the adequacy of the factor analysis. The value of $\mathrm{KMO}$ as 0.75 at a meaning level of 0.00 (Bartlett's sphericity test) showed an adequate common variance in the inter-correlation framework to make the factor analysis advantageous. The acceptable minimum KMO value was 0.5 (Nunnally, 1978). Twenty-three items were used for 
an EFA to identify the dimensional structure of the variables. In the process of EFA, principal component analysis with varimax rotation was applied to specify the relationships of the observed indicators to their posited underlying factors. Here, factor loading above 0.4 was found in EFA (Kaiser, 1958). The results show that loading in most of the factors was above 0.4 , except CM, as shown in Table 1. Therefore, CM was eliminated for further analysis. The cumulative percentage of variance (CPVE) obtained with four factors was 78.01 percent. Finally, four dimensions with 21 items were identified for further CFA test. The four dimensions were categorized as: (1) intra HRM-SCM; (2) joint HRM-SCM; (3) SCI, and (4) SCP.

Table 1: Exploratory analysis

\begin{tabular}{|c|c|c|c|c|}
\hline Construct/Indicator & Item & Mean (SD) & Factor loading & CPVE \\
\hline \multirow[t]{6}{*}{ Intra HRM-SCM } & IHRM-SCM_SKA & $4.27(1.46)$ & 0.725 & 30.43 \\
\hline & IHRM-SCM_R\&S & $4.43(1.65)$ & 0.890 & \\
\hline & IHRM-SCM_T\&D & $4.58(1.31)$ & 0.823 & \\
\hline & IHRM-SCM_PM & $4.23(1.45)$ & 0.742 & \\
\hline & IHRM-SCM_RM & $4.69(1.28)$ & 0.514 & \\
\hline & IHRM-SCM_CM & $4.32(1.76)$ & 0.385 & \\
\hline \multirow[t]{7}{*}{ SCI } & SCI_CL & $5.9(1.11)$ & 0.834 & 42.3 \\
\hline & SCI_CI & $5.87(1.05)$ & 0.717 & \\
\hline & SCI_SR & $4.31(1.57)$ & 0.950 & \\
\hline & SCI_SSP & $4.03(1.07)$ & 0.525 & \\
\hline & SCI_LTC & $4.06(1.39)$ & 0.799 & \\
\hline & SCI_MC & $4.18(1.26)$ & 0.524 & \\
\hline & SCI_Comp & $4.21(1.32)$ & 0.613 & \\
\hline \multirow[t]{6}{*}{ Joint HRM-SCM } & IHRM-SCM_SKA & $5.27(1.16)$ & 0.823 & 62.43 \\
\hline & IHRM-SCM_R\&S & $5.43(1.15)$ & 0.790 & \\
\hline & IHRM-SCM_T\&D & $5.58(1.21)$ & 0.725 & \\
\hline & IHRM-SCM_PM & $5.23(1.15)$ & 0.682 & \\
\hline & IHRM-SCM_R\&M & $5.69(1.08)$ & 0.594 & \\
\hline & IHRM-SCM_CM & $5.23(1.56)$ & 0.334 & \\
\hline SCP & SCP_OD & $5.34(1.34)$ & 0.868 & 78.21 \\
\hline
\end{tabular}




$\begin{array}{lll}\text { SCP_MS } & 5.50(1.19) & 0.844 \\ \text { SCP_ROI } & 5.04(1.20) & 0.825 \\ \text { SCP_TIC } & 5.22(1.57) & 0.770\end{array}$

\subsection{Measurement model: $\mathrm{CFA}$}

A CFA test was conducted to verify the constructs and variables for reliability, convergent validity, and discriminant validity (Hair et al., 2006). The program software, IBM SPSS 19 was used to measure the reliability and validity of the measuring items. Besides, multicollinearity testing was performed (Henseler et al., 2009). The variation inflation factor was tested and the threshold value of 3.3 was not surpassed, thus confirming multi-collinearity (Diamantopoulos and Siguaw, 2006; Jimenez-Para et al., 2014). Using the program recommended by Fornell and Larcker (1981), the Cronbach scores $(\alpha)$ and Composite Reliability (CR) of each sub-construction were evaluated. The CR exceeded the threshold value of 0.6 for all four constructs (Bagozzi and Yi, 1988). Besides, Cronbach's $\alpha$-value exceeded the recommended value of 0.7 for all factors (Nunally and Bernstein, 1994) (see Table 2 for results). These values provide evidence of internal consistency of the data. Later, the Average Variance Extracted (AVE) was used to test the convergent validity of all constructs (Fornell and Larcker, 1981; Koufteros, 1999). All constructs exceeded the recommended value of 0.5 (Fornell and Larcker, 1981) (see Table 2). In the end, as shown in Table 3, discriminant validity was established from AVE. It was evaluated by comparing the squared correlation between two latent variables using their respective AVE estimates (Fornell and Larcker, 1981). Discriminating validity exists when the average variance shared is greater than the approximate correlation square between the shared construct and its indicators (Fornell and Larcker, 1981). None of the diagonal values in Table 3 were found to be lower than the inter-constructed correlations, suggesting discriminant validity.

Table 2: Convergent validity and construct reliability

\begin{tabular}{lccccc}
\hline \multicolumn{1}{c}{ Construct } & Item & $\begin{array}{c}\text { Standardized } \\
\text { loading }\end{array}$ & CR & AVE & Cronbach's \\
\hline Intra HRM- & IHRM-SCM & 0.818 & 0.764 & 0.519 & $\boldsymbol{\alpha}$ \\
SCM & -SKA & & & & \\
& IHRM-SCM & 0.726 & & & \\
& -R\&S & & & & \\
\hline
\end{tabular}


Jena, S. K. and Ghadge, A. (2021), An integrated supply chain - human resource management approach for improved supply chain performance, International Journal of Logistics Management (DOI: 10.1108/IJLM-03-2020-0151).

\begin{tabular}{|c|c|c|c|c|c|}
\hline & IHRM-SCM & 0.677 & & & \\
\hline & $-\mathrm{T} \& \mathrm{D}$ & & & & \\
\hline & IHRM-SCM_PM & 0.512 & & & \\
\hline & IHRM-SCM_RM & 0.504 & & & \\
\hline \multirow[t]{7}{*}{ SCI } & SCI_CL & 0.736 & 0.742 & 0.580 & 0.806 \\
\hline & SCI_CI & 0.712 & & & \\
\hline & SCI_SR & 0.542 & & & \\
\hline & SCI_SSP & 0.542 & & & \\
\hline & SCI_LTC & 0.664 & & & \\
\hline & SCI_MC & 0.772 & & & \\
\hline & SCI_Comp & 0.731 & 0.779 & 0.575 & 0.776 \\
\hline \multirow{9}{*}{$\begin{array}{l}\text { Joint HRM- } \\
\text { SCM }\end{array}$} & JHRM-SCM & 0.628 & & & \\
\hline & SKA & & & & \\
\hline & JHRM-SCM & 0.825 & & & \\
\hline & - R\&S & & & & \\
\hline & JHRM-SCM & 0.795 & & & \\
\hline & ${ }_{-}^{\mathrm{T}} \& \mathrm{D}$ & & & & \\
\hline & JHRM-SCM_PM & 0.800 & 0.761 & 0.641 & 0.760 \\
\hline & JHRM-SCM & 0.708 & & & \\
\hline & R\&M & & & & \\
\hline \multirow[t]{4}{*}{$\mathrm{SCP}$} & SCP_OD & 0.877 & & & \\
\hline & SCP_MS & 0.750 & & & \\
\hline & $\mathrm{SCP}$ ROI & 0.895 & 0.869 & 0.710 & 0.831 \\
\hline & SCP_TIC & 0.751 & & & \\
\hline
\end{tabular}

Table 3: Analysis of discriminant validity

\begin{tabular}{lcccc}
\hline & Intra HRM- & SCI & Joint HRM- & \multirow{2}{*}{ SP } \\
& SCM & & SCM & \\
\hline Intra HRM-SCM & 0.984 & & & \\
SCI & 0.124 & 0.747 & & \\
Joint HRM-SCM & 0.385 & 0.441 & 0.762 & \multirow{2}{*}{0.889} \\
SP & 0.228 & 0.318 & 0.373 & \\
\hline
\end{tabular}




\subsection{Structural model: structural equation analysis}

The structural model was used, as shown in Figure 2 to assess and test the causal relationships between the constructs. The outcome of the overall goodness of fit was determined by the application of the $\chi^{2}$ test. The ratio of $\chi^{2}$ to the degree of freedom $d f$ was 2.832 , which is not greater than the proposed limit value of 5 (Bagozzi et al., 1991; Hair et al., 2006). In addition, the results of the goodness of fit measure supported the proposed model (IFI $=0.931$, $\mathrm{CFI}=0.940, \chi^{2} / d f=2.832$; RMSEA=0.052). The recommended value also satisfied RMSEA, GFI and IFI, as shown in Table 4. Therefore, it is depicted that there is a good fit amid the model and the data observed.

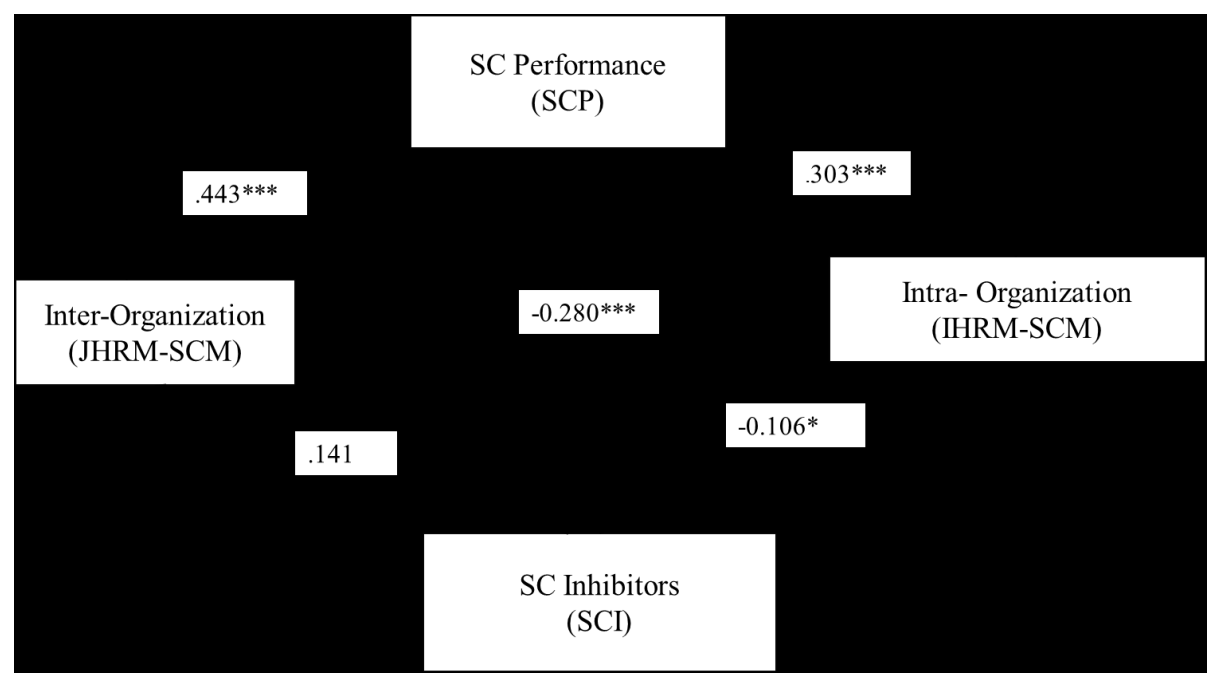

Figure 2. Results of the structural model

Note: For JHRM-SCM, $R^{2} \rightarrow .80$; For IHRM-SCM, $R^{2} \rightarrow .68$; For SCI, $R^{2} \rightarrow .61 ;$ For SCP,

$$
R^{2} \rightarrow .75
$$

*** path is significant at .01; * path is significant at .1.

Table 4: Goodness-of-fit measures for the theoretical model

\begin{tabular}{llcc}
\hline Measure & Measurement & $\begin{array}{r}\text { Recommended value } \\
\text { (Hair et al., 2006) }\end{array}$ & $\begin{array}{r}\text { Model } \\
\text { output }\end{array}$ \\
\hline$\chi^{2} /$ Degree of & Chi-square relation & Recommended value $<5$ & 2.832 \\
Freedom $(d f)$ & Degree of Freedom & & \\
CFI & Comparative Fit Index & CFI acceptable $>0.9$ & 0.940 \\
IFI & Incremental Fit Index & IFI acceptable $>0.9$ & 0.931 \\
\hline
\end{tabular}


Jena, S. K. and Ghadge, A. (2021), An integrated supply chain - human resource management approach for improved supply chain performance, International Journal of Logistics Management

(DOI: 10.1108/IJLM-03-2020-0151).

RMSEA Root mean square of approximation

RMSEA acceptable $<0.08$

0.052

\subsection{Test of hypotheses}

The structural equation model was studied by checking the arithmetic test values of the standardized path coefficient ( $\beta$ ) (see Table 5) and the value of $R^{2}$ for SCP. The $R^{2}$ value was measured as 0.75 , which means that the proposed construct explains $75.0 \%$ of the variance of SCP. Further, $R^{2}$ values for intra HRM-SCM, joint HRM-SCM, and SCI are 0.68, 0.81, and 0.61 , respectively, which convey that variance explained is high. As per the findings, the significant path coefficients indicated with * and non-significant paths are represented as dotted lines. The standardized path coefficient between the constructs is shown in Fig. 2. It is thus evident that all the paths are significant.

Table 5: Sequential model

\begin{tabular}{lcccc}
\hline \multicolumn{1}{c}{ Hypothesis } & $\boldsymbol{\beta}$ & $\mathbf{t}$ & $\mathbf{p}$ & Decision \\
\hline H1: IHRM-SCM $\rightarrow$ SCP & 0.303 & 0.139 & 0.000 & supported \\
H2a and & 0.443 & 2.619 & 0.000 & Supported \\
H2b: JHRM-SCM $\rightarrow$ SCP & & & & \\
H3: SCI $\rightarrow$ IHRM-SCM & -0.106 & -0.056 & 0.080 & supported \\
H4: SCI $\rightarrow$ JHRM-SCM & 0.141 & 1.719 & 0.187 & Not Supported \\
H5: SCI $\rightarrow$ SCP & -0.280 & 4.051 & 0.000 & Supported \\
\hline
\end{tabular}

The hypotheses results following SEM testing are presented in Table 4. It is found that there is a significant relationship between SCP and intra HRM-SCM and SCP and joint HRMSCM. H1 $(\beta=0.303, p<0.01)$ and H2 $(\beta=0.443, p<0.01)$ are supported. These findings are not particularly surprising but aim to comprehend the benefits of integrating HR practices with SCs. Similarly, Table 5 shows that, for H3 and H5, the SCI has a strong relationship with implementation of intra HRM-SCM $(\beta=-0.106, p<0.1)$ and SCP $(\beta=-0.280, p<0.01)$. As a result, $\mathrm{H} 3$ and $\mathrm{H} 5$ are supported. This indicates that SCI affects SCP and HRM, which supports Hohenstein et al. (2014) 's views that inhibitors have a negative impact. H4 is not supported $(\beta=.141, p>0.05)$ because of the knowledge and skill-sharing between HRM and SCM managers, which supports the views of Blome et al. (2014) and Qrunfleh and Tarafdar (2014). As a result, SCP increases with collaboration between the two departments (human resource and supply chain management). 


\section{Discussion and implications}

\subsection{Discussion}

The study results indicate that the impact of joint HRM-SCM on SCP is higher than intra HRMSCM. Thus, organizational performance can be improved through joint HRM-SCM. From the results, it is found that $T \& D, R \& S$, and PM affect joint HRM-SCM more when compared with the other three factors; meanwhile, in intra HRM-SCM, SKA impacts more on SCP compared to the other factors. It is also observed that logistics organizations need to pay more attention to training and development and performance management under the joint HRM-SCM strategy for improving the overall SC performance. The findings of this study support hypotheses $\mathrm{H} 1$, $\mathrm{H} 2, \mathrm{H} 3$, and $\mathrm{H} 5$, but reject hypothesis H4. This reveals that intra HRM-SCM is significantly and positively related to performance management and reward management, and not to the culture, SR, SSMP, and CI. Some of the previous studies reveal that performance management positively influences logistics and supply chain competency. One possible explanation comes from Ding et al. (2015), who state that performance management and reward management are not significantly related to logistics and supply chain competency. Meanwhile, the logistics firms of joint HRM-SCM strategy are significantly and positively related to all the indicators. These results trigger several interesting insights that deserve elaboration.

First, the significant, positive, and direct relationship between the HRM and SCM imply that effective HR policies and procedures can help to improve Indian logistics firms' supply chain performance. This finding confirms earlier empirical studies by Kam et al. (2010). Second, the significant positive relationship between joint HRM-SCM and SCP suggests that to create a common goal and enhance the skill of the staff, knowledge sharing, and effective training and development programmers are necessary. As a result, they will contribute to improvement in the supply chain performance of logistics firms in India. The recruitment and selection process can help the logistics firms of India establish a desirable workforce, which can provide a unique advantage to these firms in terms of improved performance.

Similarly, because of the integration of HRM with SCM, rewards management practices can also be designed to retain the performing staff within and between the organizations. Equity theory (Adams and Freedman, 1976) claims that staff members are more driven to contribute to collaborative tasks when they observe that the unbiased reward treatment is being exercised. Thus, it is evident that the integration of HRM with SCM helps create a common platform for HR and SC managers to collaborate to enable knowledge enhancement. Some of the findings are consistent with previous studies conducted in different regions or sectors (e.g., Ding et al., 2015; Hohenstein et al., 2014). 
Third, hypothesis H3 and H5 show a negative and strong direct connection between SCI with SCP and IHRM-SCM. These findings demonstrate a requirement for considering the impact of certain potential hindrances (e.g., culture, cost suggestion, showcase correspondence, and LTC) to viable usage of coordination of HRM-SCM resources. Furthermore, the analysis highlights that SCI has a non-significant impact on the JHRM-SCM because of the collaboration and joint HRM and SCM practices. This indicates that SC performance cannot be affected by SCI under joint HRM-SCM practices. As a result, the supply chain's performance will improve under joint HRM-SCM compared to an intra HRM-SCM strategy.

\subsection{Implications for research and practice}

Implementation of joint HRM-SCM for improving SCP is at a nascent phase in a developing country like India. This study will strengthen the opinion of the logistics and other associated service firms regarding the adoption of HRM practices in SCs. The Indian automotive industry is fragmented into large (OEMs) and small players (SMEs \& MSMEs), but integration of HRM with an SCM focus is mostly limited to only large and tier-one suppliers. Other players like MSMEs and unorganized sector organizations need to shift to SCM integration with HRM.

From a practical point of view, this study can contribute to achieving strong supply chain performance of organizations by directing their managers to link intra and joint strategic objectives with specific HRM and SCM practices. This linkage can generate the deep involvement of staff in shaping joint HRM-SCM practices. Primarily, an empirically based argument is outlined for organizations to invest in a model of integration of HRM and SCM, which appeals to human resource managers and supply chain managers, as such action may enhance the company's performance. Second, the study result depicts a guideline for managers to pay attention to the perception of downward and upward SC members towards the collaboration of HRM-SCM practices through culture and knowledge sharing. The logistics manager should continue with dedicated investment in the joint HRM-SCM strategy to minimize the negative impact of SCI on SCP. Third, the result of this work shows that joint HRM-SCM is affected by T\&D, R\&S, and PM positively, while intra HRM-SCM is affected significantly by SKA. This result also provides advice to the logistics manager for creating a collaborative strategy among the firms on training and development and the recruitment and selection process, to improve the organisation's performance. Fourth, by understanding the association between HR and SC practices, the firm can make trade-offs about SCP measures.

The findings concerning HRM-SCM integration will help SC managers to develop well-informed HRM practices within and between organizations. Such integrated managerial 
philosophy is potentially a source of competitive advantage, highlighting the importance of continuous improvement and learning that is often allied to effective performance (GonzalezLoureiro et al., 2014).

Indian logistics firms need to consider training and development, and recruitment and selection process jointly because these factors play an important role in improving SCP. It is also observed that cost implications, market communication, and cultural diversity have a negative impact on intra HRM and SCP. Central training programs should be arranged for all logistics and automotive firms to obtain new skills and remove the inhibitors to intra HRMSCM. During our survey, a senior logistics manager mentioned that "joint HRM and SCM is an important strategy for on-time delivery and return on investment'. Multiple firms have confirmed that critical issues such as the shortage of logistics human resources and lack of logistics expertise hamper supply chain performance. This problem can be minimized, if we share resources and knowledge within and between logistics firms and departments. However, we perceive that this is not successfully happening because of cultural differences and competition between firms. Moreover, HR managers do not have in-depth knowledge of the supply chain and, similarly, SC managers do not have sufficient knowledge of HR practices. Furthermore, during the interaction with supply chain managers, it was discovered that OEMs need to improve the frequency of their training programs for implementing HRM-SCM practices between firms.

The research contributions of this paper are four-fold. Firstly, this paper incorporates integration of HRM and SCM practices in a supply chain, based on the following literature (Guinipero et al., 2008; Fisher et al., 2010; Farndale et al., 2010; Pandey et al., 2012; Sweeney, 2013; Ellinger and Ellinger, 2014; Hohenstein et al., 2014; Ding et al., 2015; D’Aleo and Sergi, 2017). Secondly, this paper develops a conceptual framework considering the relationships between JHRM-SCM and IHRM-SCM on SCP (Lengick-Hall et al., 2013; Hohenstein et al., 2014; Guersola et al., 2018), SCI on SCP (Bayraktar et al., 2009; Gopal and Thakker, 2016; Tatoglu et al., 2016), and SCI on JHRM-SCM and IHRM-SCM (Fisher et al., 2010). Thirdly, it analyzes the perception of supply chain and human resource experts concerning the effect of the JHRM-SCM and IHRM-SCM strategy on SCP in an Indian automobile and logistics sector. Finally, it was found that SCP is significantly influenced by joint HRM-SCM compared to intra HRM-SCM under training and development, and recruitment and selection. This result is different from that of existing literature (Ellinger and Ellinger, 2014; Hohenstein et al., 2014; Ding et al., 2015; Tatoglu et al., 2016; Flothmann et al. 2018; Guersola et al., 2018; Agyabeng-Mensah et al., 2020). 
This study evidence that logistics firms need to take care of their employees or SC managers' skills and knowledge to execute good HRM practices. HRM and SCM professionals should understand SC partners' organizational cultures to provide adequate support and motivate them to integrate HRM-SCM practices. Training and development programs benefit organizations by helping them to align HR practices with SC objectives. While interacting with SC managers and HR professionals, the need for logistics firms to develop training programs for providing sector-specific skills and knowledge to benefit the integration of HRM activities was strongly felt by supply chain managers.

\section{Conclusions and future research}

The study provides extension and applicability of knowledge-based theory for the adoption of integrated HRM and SCM practices. It identifies various cues that firms use for improving SCP. The study also examines the effect of intra HRM-SCM and joint HRM-SCM on SCP and explores SCP drivers from an HRM perspective. The study developed multiple hypotheses and tested them empirically following a proposed model for the Indian logistics industry. The proposed model will help Indian logistics to make integrated HRM-SCM decisions for improved supply chain performance. These results advance the current knowledge concerning the HRM and SCM interface and help both human resource and supply chain managers take substantial managerial decisions to improve total SCP.

The paper contributes to the existing literature as follows. Firstly, the relationship between intra HRM-SCM, joint HRM-SCM, and SCI with SCP has been empirically established in this study. Second, based on the results, factors are arranged according to the significance of SCP under intra HRM-SCM and joint HRM-SCM practices. Furthermore, some managerial implications are listed to adopt the integration of HRM with SCM such as central adoption of training, requirements, and selection synchronizing with the industry, etc.

As with any research, this study has some limitations, and they pave the way for future research. The sample chosen for the study is relatively small and larger size data would have been helpful to conduct a comprehensive study. Further research is required to make confident generalizations following a larger sample size. Additional exploration is anticipated to make the results more generalized by considering firms' cultural, economic, geographic, and demographic differences. Given that all the participating logistics organizations were from the same country (i.e. India), and since the knowledge sharing, culture and institutional background could influence HRM and SCM practices and their performance, this may limit the generalizability of the results drawn in this paper. 
Furthermore, this research introduces a perception-based empirical analysis of potential performance effects that are not traditionally used in logistics firms but are fit to address the integration of managerial practices in such samples. We recommend investigating the effect of joint HRM-SCM practices by considering agility and positioning competence on SCP. In addition, the conceptual framework of this study could be extended to examine the impact of joint HRM-SCM practices on SCP considering the influence of Industry 4.0 applications.

\section{References}

Adams, J. S., \& Freedman, S. (1976). Equity theory revisited: Comments and annotated bibliography. In Advances in experimental social psychology (Vol. 9, pp. 43-90). Academic Press.

Agyabeng-Mensah, Y., Ahenkorah, E., Afum, E., Agyemang, A. N., Agnikpe, C., \& Rogers, F. (2020). Examining the influence of internal green supply chain practices, green human resource management and supply chain environmental cooperation on firm performance. Supply Chain Management: An International Journal (In press).

Ahmad, S., \& Schroeder, R. G. (2003). The impact of human resource management practices on operational performance: recognizing country and industry differences. Journal of operations Management, 21(1), 19-43.

Armstrong, J. S., \& Overton, T. S. 1997. Estimating non-response bias in mail surveys. Journal of marketing research, 396-402.

Bagozzi, R. P., \& Yi, Y. 1988. On the evaluation of structural equation models. Journal of the academy of marketing science, 16(1), 74-94.

Bagozzi, R. P., Yi, Y., \& Phillips, L. W. 1991. Assessing construct validity in organizational research. Administrative science quarterly, 421-458.

Barnes, J., \& Liao, Y. (2012). The effect of individual, network, and collaborative competencies on the supply chain management system. International Journal of Production Economics, 140(2), 888-899.

Barney, J. B. (1991). Firm resources and sustained competitive advantage. Journal of Management, 17(1), 99-120.

Bayraktar, E., Demirbag, M., Koh, S. L., Tatoglu, E., \& Zaim, H. (2009). A causal analysis of the impact of information systems and supply chain management practices on operational performance: evidence from manufacturing SMEs in Turkey. International Journal of Production Economics, 122(1), 133-149.

Bendickson, J. S., \& Chandler, T. D. (2019). Operational performance: The mediator between human capital developmental programs and financial performance. Journal of Business Research, 94, 162-171.

Blome, C., Schoenherr, T., \& Eckstein, D. (2014). The impact of knowledge transfer and complexity on supply chain flexibility: A knowledge-based view. International Journal of Production Economics, 147, 307-316.

Braunscheidel, M. J., Suresh, N. C., \& Boisnier, A. D. (2010). Investigating the impact of organizational culture on supply chain integration. Human Resource Management, 49(5), 883-911.

Burnes, B. 2004. Managing change: A strategic approach to organizational dynamics. Pearson Education.

Bureau ET (2020) Labour shortage may break supply chain in Coronavirus lockdown extension https://economictimes.indiatimes.com/news/politics-and-nation/labour-shortage-may- 
break-supply-chain-in-lockdown-extension/articleshow/75073078.cms (Accessed on 16th April 2021).

Cakar, F., Bititci, U. S., \& MacBryde, J. (2003). A business process approach to human resource management. Business Process Management Journal, 9(2), 190-207

Cao, M., \& Zhang, Q. (2011). Supply chain collaboration: Impact on collaborative advantage and firm performance. Journal of operations management, 29(3), 163-180.

Chand, M., \& Katou, A. A. 2007. The impact of HRM practices on organizational performance in the Indian hotel industry. Employee Relations, 29(6), 576-594.

Charan, P., Shankar, R., \& Baisya, R. K. (2008). Analysis of interactions among the variables of supply chain performance measurement system implementation. Business Process Management Journal 14 (4), 512-529.

Chen, I. J., \& Paulraj, A. 2004. Towards a theory of supply chain management: the constructs and measurements. Journal of operations management, 22(2), 119-150.

Choi, B., Poon, S. K., \& Davis, J. G. (2008). Effects of knowledge management strategy on organizational performance: A complementarity theory-based approach. Omega, 36(2), 235-251.

Craighead, C. W., Hult, G. T. M., \& Ketchen Jr, D. J. (2009). The effects of innovation-cost strategy, knowledge, and action in the supply chain on firm performance. Journal of Operations Management, 27(5), 405-421.

D'Aleo, V., \& Sergi, B. S. (2017). Human factor: the competitive advantage driver of the EU's logistics sector. International journal of production research, 55(3), 642-655.

Daugherty, P.J., R.F. Lusch, M. B. Myers, and D.A. Griffith.2000. Linking Compensation and Retention. Supply chain management review 4(4):64-72.

Delaney, J. T., \& Huselid, M. A. 1996. The impact of human resource management practices on perceptions of organizational performance. Academy of Management journal, 39(4), 949-969.

Diamantopoulos, A., \& Siguaw, J. A. 2006. Formative versus reflective indicators in organizational measure development: A comparison and empirical illustration. British Journal of Management, 17(4), 263-282.

Ding, M. J., Kam, B. H., Zhang, J. Y., \& Jie, F. 2015. Effects of human resource management practices on logistics and supply chain competencies-evidence from China logistics service market. International Journal of Production Research, 53(10), 2885-2903.

Dittmann, J. P. (2012). Supply chain transformation: Building and executing an integrated supply chain strategy. McGraw Hill Professional.

Doty, D. H., \& Glick, W. H. (1998). Common methods bias: does common methods variance really bias results? Organizational research methods, 1(4), 374-406.

Ellinger, A. E., Ellinger, A. D., \& Keller, S. B. 2005. Supervisory coaching in a logistics context. International journal of physical distribution \& logistics management, 35(9), 620-636.

Ellinger, A. E, \& Ellinger, A. D. 2014. Leveraging human resource development expertise to improve supply chain managers' skills and competencies. European Journal of Training and Development, 38(1/2), 118-135.

Ellinger, A.E., Natarajarathinam, M., Adams, F.G., Gray, J.B., Hofman, D. and O’Marah, K. (2011), "Supply chain management competency and firm financial success", Journal of Business Logistics, Vol. 32 No. 3, pp. 214-226.

Ellinger, A., Shin, H., Magnus Northington, W., Adams, F. G., Hofman, D., \& O'Marah, K. 2012. The influence of supply chain management competency on customer satisfaction and shareholder value. Supply Chain Management: An International Journal, 17(3), 249262. 
Faisal, M. N. (2015). A study of inhibitors to transparency in red meat supply chains in Gulf cooperation council (GCC) countries. Business Process Management Journal, 21(6), 1299-1318.

Farndale, E., Paauwe, J., \& Boselie, P. 2010. An exploratory study of governance in the intrafirm human resources supply chain. Human Resource Management, 49(5), 849-868.

Fawcett, S. E., Magnan, G. M., \& McCarter, M. W. (2008). Benefits, barriers, and bridges to effective supply chain management. Supply Chain Management: An International Journal, 13(1), 35-48.

Fisher, S. L., Graham, M. E., Vachon, S., \& Vereecke, A. 2010. Guest Editors' Note: Don't miss the boat: Research on HRM and supply chains. Human Resource Management, 49(5), 813-828.

Flöthmann, C., Hoberg, K., \& Gammelgaard, B. (2018). Disentangling supply chain management competencies and their impact on performance. International Journal of Physical Distribution \& Logistics Management.

Fong, C., K. Ooi, B. Tan, and V. Lee. 2011. "HRM Practices and Knowledge Sharing: An Empirical Study.” International Journal of Manpower 32 (5/6): 704-723.

Fornell, C., \& Larcker, D. F. 1981. Structural equation models with unobservable variables and measurement error: Algebra and statistics. Journal of marketing research, 382-388.

Ganga, G. M. D., Carpinetti, L. C. R., \& Politano, P. R. (2011). A fuzzy logic approach to supply chain performance management. Gestão \& produção, 18(4), 755-774.

Gattorna, J. 2006. Living supply chains: how to mobilize the enterprise around delivering what your customers want. Pearson Education.

Giunipero, L., Handfield, R. B., \& Eltantawy, R. 2006. Supply management's evolution: key skill sets for the supply manager of the future. International Journal of Operations \& Production Management, 26(7), 822-844.

Gmelin, H., \& Seuring, S. (2014). Determinants of a sustainable new product development. Journal of Cleaner production, 69, 1-9.

Gómez-Cedeño, M., Castán-Farrero, J. M., Guitart-Tarrés, L., \& Matute-Vallejo, J. (2015). Impact of human resources on supply chain management and performance. Industrial Management \& Data Systems, 115(1), 129-157.

González-Loureiro, M., Dabić, M., \& Puig, F. (2014). Global organizations and supply chain: new research avenues in the international human resource management. International Journal of Physical Distribution \& Logistics Management, 44(8/9), 689-712.

Gopal, P. R. C., \& Thakkar, J. 2016. Sustainable supply chain practices: an empirical investigation on Indian automobile industry. Production Planning \& Control, 27(1), 4964.

Govindan, K., \& Hasanagic, M. (2018). A systematic review on drivers, barriers, and practices towards circular economy: a supply chain perspective. International Journal of Production Research, 56(1-2), 278-311.

Gowen III, C. R., McFadden, K. L., \& Tallon, W. J. (2006). On the centrality of strategic human resource management for healthcare quality results and competitive advantage. Journal of Management Development, 25(8), 806-826.

Grant, R. M. (1996). Toward a knowledge-based theory of the firm. Strategic management journal, 17(S2), 109-122.

González-Loureiro, M., Dabić, M., \& Puig, F. (2014). Global organizations and supply chain: new research avenues in the international human resource management. International Journal of Physical Distribution \& Logistics Management, 44(8/9), 689-712.

Guersola, M., Lima, E. P. D., \& Steiner, M. T. A. (2018). Supply chain performance measurement: a systematic literature review. International Journal of Logistics Systems and Management, 31(1), 109-131. 
Guerci, M., Longoni, A., \& Luzzini, D. (2016). Translating stakeholder pressures into environmental performance-the mediating role of green HRM practices. The International Journal of Human Resource Management, 27(2), 262-289.

Gunasekaran, A., Patel, C., \& McGaughey, R. E. (2004). A framework for supply chain performance measurement. International journal of production economics, 87(3), 333347.

Gupta, S; Huddar, N; Iyer, B; Moller, T. (2018). The future of mobility in Indian's passenger -vehicle market. https://www.mckinsey.com/industries/automotive-and-assembly/ourinsights/the-future-of-mobility-in-indias-passenger-vehicle-market (Accessed on 16th April 2021).

Hair, J. F., Black, W. C., Babin, B. J., Anderson, R. E., \& Tatham, R. L. (2006). EM: confirmatory factor analysis. Multivariate data analysis. Pearson, 770-842.

Hassini, E., Surti, C., \& Searcy, C. (2012). A literature review and a case study of sustainable supply chains with a focus on metrics. International Journal of Production Economics, 140(1), 69-82.

Henseler, J., Ringle, C. M., \& Sinkovics, R. R. 2009. The use of partial least squares path modeling in international marketing. Advances in international marketing, 20(1), 277319.

Ho, D. C., Au, K. F., \& Newton, E. 2002. Empirical research on supply chain management: a critical review and recommendations. International Journal of Production Research, 40(17), 4415-4430.

Hohenstein, N. O., Feisel, E., \& Hartmann, E. 2014. Human resource management issues in supply chain management research: A systematic literature review from 1998 to 2014 . International Journal of Physical Distribution \& Logistics Management, 44(6), 434-463.

Huo, B., Han, Z., Chen, H., \& Zhao, X. (2015). The effect of high-involvement human resource management practices on supply chain integration. International Journal of Physical Distribution \& Logistics Management.

Huo, B., Wang, Z., \& Tian, Y. (2016). The impact of justice on collaborative and opportunistic behaviors in supply chain relationships. International Journal of Production Economics, 177, 12-23.

Jabbour, C. J. C., \& de Sousa Jabbour, A. B. L. 2016. Green human resource management and green supply chain management: Linking two emerging agendas. Journal of Cleaner Production, 112, 1824-1833.

Jiménez-Parra, B., Rubio, S., \& Vicente-Molina, M. A. (2014). Key drivers in the behavior of potential consumers of remanufactured products: a study on laptops in Spain. Journal of Cleaner Production, 85, 488-496.

Jena, S. K., \& Sarmah, S. P. 2015. Measurement of consumers' return intention index towards returning the used products. Journal of Cleaner Production, 108, 818-829.

Joshi, D., Nepal, B., Rathore, A.P.S. and Sharma, D. (2013) 'On supply chain competitiveness of Indian automotive component manufacturing industry', International Journal of Production Economics, 143 (1), 151-161.

Kaiser, H. F. 1958. The varimax criterion for analytic rotation in factor analysis. Psychometrika, 23(3), 187-200.

Kaliani Sundram, V. P., Chandran, V. G. R., \& Awais Bhatti, M. (2016). Supply chain practices and performance: the indirect effects of supply chain integration. Benchmarking: An International Journal, 23(6), 1445-1471.

Kam, B. H., Tsahuridu, E. E., \& Ding, M. J. 2010. Does human resource management contribute to the development of logistics and supply chain capabilities? An empirical study of logistics service providers in China. Research and Practice in Human Resource Management, 18(2). 
Ketchen, D. J., \& Hault, G. T. M. 2007. Bridging organization theory and supply chain management: The case of best value supply chains. Journal of Operations Management, 25(2), 573-580.

Koulikoff-Souviron, M., \& Harrison, A. 2010. Evolving HR practices in a strategic intra-firm supply chain. Human resource management, 49(5), 913-938.

Kumar, A., Mangla, S. K., Luthra, S., \& Ishizaka, A. (2019). Evaluating the human resource related soft dimensions in green supply chain management implementation. Production Planning \& Control, 30(9), 699-715.

LCLogistics India, 2011, Logics India http://www.lcllogistix.com/pdf/white paper.pdf (Accessed on 16th April 2021).

Lengnick-Hall, M. L., Lengnick-Hall, C. A., \& Rigsbee, C. M. 2013. Strategic human resource management and supply chain orientation. Human Resource Management Review, 23(4), 366-377.

Li \& Fung limited (2012) https://www.lifung.com/wp content/uploads/2013/03/ar2012 09.pdf (Accessed on 16th April 2021).

Lieb, R. (2008). The North American third-party logistics industry in 2007: the provider CEO perspective. Transportation journal, 47(2), 39-53.

Liu, Y., Blome, C., Sanderson, J., \& Paulraj, A. (2018). Supply chain integration capabilities, green design strategy and performance: a comparative study in the auto industry. Supply Chain Management: An International Journal, 23(5), 431-443.

Luthra, S., Kumar, V., Kumar, S., \& Haleem, A. 2011. Barriers to implement green supply chain management in automobile industry using interpretive structural modeling technique: An Indian perspective. Journal of Industrial Engineering and Management, 4(2), 231-257.

Maiden, T. How Big Is the Logistics Industry? FreightWaves. Available online: https://www. freightwaves. com/news/how-big-is-the-logistics-industry (accessed on 11 January 2020).

McAfee, R. B., Glassman, M., \& Honeycutt, E. D. 2002. The effects of culture and human resource management policies on supply chain management strategy. Journal of Business logistics, 23(1), 1-18.

Mentzer, J. T., Stank, T. P., \& Esper, T. L. (2008). Supply chain management and its relationship to logistics, marketing, production, and operations management. Journal of Business Logistics, 29(1), 31-46.

Mitra, S., \& Datta, P. P. (2014). Adoption of green supply chain management practices and their impact on performance: an exploratory study of Indian manufacturing firms. International Journal of Production Research, 52(7), 2085-2107.

Murphy, P. R., \& Poist, R. F. 2006. Skill requirements of contemporary senior-and entry-level logistics managers: a comparative analysis. Transportation Journal, 46-60.

Nunnally J C. 1978. Psychometric theory. Psychometric methods New York: McGraw Hill, $640 \mathrm{p}$.

Nunally, J. C., \& Bernstein, I. H. 1994. Psychonometric theory. New York.

Othman, R., \& Abdul Ghani, R. 2008. Supply chain management and suppliers' HRM practice. Supply Chain Management: An International Journal, 13(4), 259-262.

Pandey, P., Bhattacharyya, S., \& Kaur, A. 2012. Exploring the role of HR practices in supply chain. Journal of Advances in Management Research, 9(1), 113-123.

Podsakoff, P. M., MacKenzie, S. B., Lee, J. Y., \& Podsakoff, N. P. (2003). Common method biases in behavioral research: A critical review of the literature and recommended remedies. Journal of applied psychology, 88(5), 879.

Podsakoff, P. M., MacKenzie, S. B., \& Podsakoff, N. P. (2012). Sources of method bias in social science research and recommendations on how to control it. Annual review of psychology, 63, 539-569. 
Power, D. 2005. Supply chain management integration and implementation: a literature review. Supply chain management: An International journal, 10(4), 252-263.

Prajogo, D., \& Sohal, A. (2013). Supply chain professionals: A study of competencies, use of technologies, and future challenges. International Journal of Operations \& Production Management, 33(11-12), 1532-1554.

Qrunfleh, S., \& Tarafdar, M. (2014). Supply chain information systems strategy: Impacts on supply chain performance and firm performance. International Journal of Production Economics, 147, 340-350.

Rogowski, R. (2005). On the path to excellence: The impact of human interaction on supply chain management practices. Performance Improvement, 44(7), 26-33.

Saad, S., Perera, T., Achanga, P., Shehab, E., Roy, R., \& Nelder, G. (2006). Critical success factors for lean implementation within SMEs. Journal of manufacturing technology management.

Sezen, B. 2008. Relative effects of design, integration and information sharing on supply chain performance. Supply Chain Management: An International Journal, 13(3), 233-240.

Shub, A.N. and Stonebraker, P.W. (2009), "The human impact on supply chains: evaluating the importance of 'soft' areas on integration and performance", Supply Chain Management: An International Journal, 14 (1), 31-40.

Slone, R.E., Dittmann, J.P. and Mentzer, J.T. (2010), New Supply Chain Agenda: The 5 Steps That Drive Real Value, Harvard Business Press, Boston, MA.

Slone, R. E., Mentzer, J. T., \& Dittmann, J. P. (2007). Are you the weakest link in your company's supply chain? Harvard Business Review, 85(9), 116.

Stank, T. P., Dittmann, J.P., \& Autry, C. W. 2011. The new supply chain agenda: a synopsis and directions for future research. International Journal of Physical Distribution \& Logistics Management, 41(10), 940-955.

Swanson, R.A. and Holton, E.F. III (2009), Foundations of Human Resource Development, 2nd ed., Berrett-Koehler Publishers, San Francisco, CA.

Swart, W., Hall, C., \& Chen, H. (2012, January). Human performance in supply chain management. In Supply Chain Forum: An International Journal, 13(2), pp. 10-20.

Sweeney, E. (2013). The people dimension in logistics and supply chain management-its role and Importance, in passaro, R.(Eds), supply chain management: perspective, issues and cases, McGraw-Hill, pp.73-82

Tatoglu, E., Bayraktar, E., Golgeci, I., Koh, S. L., Demirbag, M., \& Zaim, S. (2016). How do supply chain management and information systems practices influence operational performance? Evidence from emerging country SMEs. International Journal of Logistics Research and Applications, 19(3), 181-199.

Tiwari, R., \& Kalogerakis, K. (2017). Innovation pathways and trajectories in India's auto component industry (No. 98). Working paper.

Tsai, W. 2001. "Knowledge Transfer in Intraorganizational Networks: Effects of Network Position and Absorptive Capacity on Business Unit Innovation and Performance." Academy of Management Journal 44 (5): 996-1004

Wang, H., Law, K. S., \& Chen, Z. X. (2008). Leader-member exchange, employee performance, and work outcomes: An empirical study in the Chinese context. The International Journal of Human Resource Management, 19(10), 1809-1824.

Wang, L., Zhao, J. Z., \& Zhou, K. Z. (2018). How do incentives motivate absorptive capacity development? The mediating role of employee learning and relational contingencies. Journal of Business Research, 85, 226-237.

Warner, M. (2008). Reassessing human resource management 'with Chinese characteristics': An overview: Introduction. The international journal of human resource management, 19(5), 771-801. 
Wu, Y.-C.J., Huang, S.K., Goh, M. and Hsieh, Y.-J. 2013. Global logistics management curriculum: perspective from practitioners in Taiwan, Supply Chain Management: An International Journal, Vol. 18 No. 4, pp. 376-388.

Zaid, A. A., Jaaron, A. A., \& Bon, A. T. (2018). The impact of green human resource management and green supply chain management practices on sustainable performance: An empirical study. Journal of cleaner production, 204, 965-979.

Zhang, Q., \& Cao, M. (2018). Exploring antecedents of supply chain collaboration: Effects of culture and interorganizational system appropriation. International Journal of Production Economics, 195, 146-157.

Zhou, H., \& Benton Jr, W. C. (2007). Supply chain practice and information sharing. Journal of Operations management, 25(6), 1348-1365.

\section{Appendix A: Description of measurement indicators}

\begin{tabular}{|c|c|c|c|}
\hline Indicators & $\begin{array}{c}\text { Short } \\
\text { term }\end{array}$ & Description & References \\
\hline \multicolumn{4}{|c|}{ HRM practices } \\
\hline $\begin{array}{l}\text { Skills } \\
\text { Knowledge }\end{array}$ & SKA & $\begin{array}{l}\text { The skills, knowledge, and } \\
\text { attributes required to perform a } \\
\text { job and are generally } \\
\text { demonstrated through qualifying } \\
\text { service, education, or training. }\end{array}$ & $\begin{array}{l}\text { Jabbour and Jabbour } \\
\text { (2016); Fisher et al. } \\
\text { (2010); McAfee et al. } \\
\text { (2002) }\end{array}$ \\
\hline $\begin{array}{l}\text { Recruitment } \\
\text { Selection }\end{array}$ & $\mathrm{R} \& \mathrm{~S}$ & $\begin{array}{l}\text { Recruitment and selection play an } \\
\text { important role in improving SCP } \\
\text { because SC performance is } \\
\text { dependent on its employees }\end{array}$ & Fisher et al. (2010) \\
\hline $\begin{array}{l}\text { Training } \\
\text { Development }\end{array}$ & $\mathrm{T} \& \mathrm{D}$ & $\begin{array}{l}\text { Firms invest in training and } \\
\text { development to reduce the } \\
\text { shortfall of the talented SC } \\
\text { professionals }\end{array}$ & $\begin{array}{l}\text { Bendickson \& } \\
\text { Chandler (2019); } \\
\text { Fisher et al. (2010); } \\
\text { Ahlstrom et al. (2001) }\end{array}$ \\
\hline $\begin{array}{l}\text { Performance } \\
\text { Management }\end{array}$ & PM & $\begin{array}{l}\text { Performance management } \\
\text { activities include some activities } \\
\text { for monitoring the progress of the } \\
\text { targets deciding rewards and } \\
\text { disciplinary actions }\end{array}$ & $\begin{array}{l}\text { Fisher et al. (2010), } \\
\text { Cakar, et al. (2003) }\end{array}$ \\
\hline Reward management & $\mathrm{RM}$ & $\begin{array}{l}\text { Reward management refers to } \\
\text { designing the merit pay or } \\
\text { compensation by the firms to the } \\
\text { employees for achieving definite } \\
\text { goals. }\end{array}$ & $\begin{array}{l}\text { Fisher et al. (2010); } \\
\text { Cakar, et al., (2003) }\end{array}$ \\
\hline Change Management & $\mathrm{CH}$ & $\begin{array}{l}\text { Change management help supply } \\
\text { chain managers, to disseminate a } \\
\text { broader understating of SCM } \\
\text { concepts within and between the } \\
\text { firms }\end{array}$ & $\begin{array}{l}\text { Fisher et al. (2010), } \\
\text { Ellinger and Ellinger, } \\
(2014)\end{array}$ \\
\hline
\end{tabular}


Jena, S. K. and Ghadge, A. (2021), An integrated supply chain - human resource management approach for improved supply chain performance, International Journal of Logistics Management

(DOI: 10.1108/IJLM-03-2020-0151).

\begin{tabular}{|c|c|c|c|}
\hline Culture & $\mathrm{CL}$ & $\begin{array}{l}\text { Lack of trust among firms in the } \\
\text { supply chain }\end{array}$ & $\begin{array}{l}\text { Gattorna (2006); } \\
\text { Braunscscheidel } \\
\text { (2010); Ellinger \& } \\
\text { Ellinger (2014); Hult et } \\
\text { al. (2007) }\end{array}$ \\
\hline Cost Implication & CI & $\begin{array}{l}\text { Cost has a major significance in } \\
\text { organizational and supply chain } \\
\text { related decisions }\end{array}$ & $\begin{array}{l}\text { Jabbour and Jabbour, } \\
(2016) \text {. }\end{array}$ \\
\hline Supplier Reluctance & SR & $\begin{array}{l}\text { SR indicates noninvolvement of } \\
\text { the suppliers in the change process } \\
\text { thus affecting overall performance } \\
\text { of the chain. }\end{array}$ & $\begin{array}{l}\text { Fawcett et al. (2008); } \\
\text { Luthra et al. (2011); } \\
\text { Gopal and Thakkar } \\
\text { (2016). }\end{array}$ \\
\hline $\begin{array}{l}\text { Shortage of Skilled } \\
\text { Professionals }\end{array}$ & SSP & $\begin{array}{l}\text { A shortage of skills professionals } \\
\text { is a source of aggravation to firms } \\
\text { and, when acute, is likely to affect } \\
\text { the quality and quantity of their } \\
\text { output. }\end{array}$ & $\begin{array}{l}\text { Fawcett et al. (2008); } \\
\text { LCLogistics, India } \\
\text { (2011) }\end{array}$ \\
\hline $\begin{array}{l}\text { Lack of } \\
\text { Management } \\
\text { Commitment }\end{array}$ & LTC & $\begin{array}{l}\text { Top management commitment } \\
\text { becomes an important factor for } \\
\text { the successful implementation of } \\
\text { the changes in the organizational } \\
\text { practices }\end{array}$ & $\begin{array}{l}\text { Fawcett et al. (2008); } \\
\text { Luthra et al. (2011); } \\
\text { Gopal and Thakkar } \\
\text { (2016) }\end{array}$ \\
\hline $\begin{array}{l}\text { Market } \\
\text { Characteristics }\end{array}$ & $\mathrm{MC}$ & $\begin{array}{l}\text { Market characteristics to which } \\
\text { the organization and supply chain } \\
\text { belongs need to be understood for } \\
\text { suitable implementation of the } \\
\text { changed processes. }\end{array}$ & $\begin{array}{l}\text { Luthra et al. (2011); } \\
\text { Gopal and Thakkar } \\
\text { (2016) }\end{array}$ \\
\hline Industry Competition & Comp & $\begin{array}{l}\text { Competitive forces affecting the } \\
\text { organization and the supply chain } \\
\text { in general }\end{array}$ & $\begin{array}{l}\text { Luthra et al. (2011); } \\
\text { Gopal and Thakkar } \\
\text { (2016) }\end{array}$ \\
\hline
\end{tabular}

\section{Supply chain performance}

\begin{tabular}{|c|c|c|c|}
\hline On Time Delivery & OD & $\begin{array}{l}\text { The key dimensions of time- } \\
\text { based performance in SCM } \\
\text { include delivery speed, new } \\
\text { product development time, } \\
\text { delivery reliability/dependability }\end{array}$ & $\begin{array}{l}\text { Chen and Paulraj } \\
\text { (2004), Gunasekkaran } \\
\text { et al. (2004); Sezen } \\
\text { (2008). }\end{array}$ \\
\hline Market Share & MS & $\begin{array}{l}\text { The proportion of market captured } \\
\text { by Firms }\end{array}$ & $\begin{array}{l}\text { Chen and Paulraj } \\
\text { (2004); Gunasekkaran } \\
\text { et al. (2004); Sezen } \\
\text { (2008). }\end{array}$ \\
\hline Return on Investment & ROI & $\begin{array}{l}\text { ROI determines the performance } \\
\text { by top management is terms of } \\
\text { earnings on the total capital } \\
\text { invested in a business }\end{array}$ & $\begin{array}{l}\text { Chen and Paulraj } \\
\text { (2004), Gunasekkaran } \\
\text { et al (2004); Sezen } \\
(2008) \text {. }\end{array}$ \\
\hline
\end{tabular}


Jena, S. K. and Ghadge, A. (2021), An integrated supply chain - human resource management approach for improved supply chain performance, International Journal of Logistics Management (DOI: 10.1108/IJLM-03-2020-0151).

\begin{tabular}{llll}
\hline Total inventory cost & TIC & $\begin{array}{l}\text { The total cost associated with } \\
\text { inventory opportunity cost, }\end{array}$ & (2004); Othman and \\
& consisting of warehousing, capita & Ghani (2008); Stank et. \\
land storage; & al. (2011)
\end{tabular}

Appendix C: Overview of analysis

Methodology

Description

Likert scale

Sampling technique

Respondent designation
Firms' services offered

Seven point

Potential contacts taken from ACMA, NHA and CII (based on convenience process)

- Sr. Manager

- Manager

- Sr. Executive

- Freight forwarding

- Transportation

- Warehousing

- Distribution

- Logistics system design

- Inventory planning and control

\section{5}

The total number
were posted to

Sample collected through

- Web base survey: $90 \%$

- Offline: $10 \%$

Number of responses received 122

Number of incomplete responses

Final sample size

Data characteristics

Exploratory factor analysis

Confirmatory factor analysis
13

109

- Nature of the data: Normality

- Mean: 4.18-5.9 (for all items)

- Standard deviation: 1.05-1.76 (for all items)

- Kaiser-Meyer-Olkin (KMO) :0.75 (>0.5)

- Bartlett's sphericity test: 0.00

- CMB tested: Harman's test

- Factor loading $>0.4$

- Total number items extracted: 21

- Total constructs: 4

- The cumulative percentage of variance (CPVE) obtained with four factors is 78.01 percent.

- Reliability: Cronbach's $\alpha$-value $>0.7$

Composite reliability $>0.6$

- Validity: Convergent validity (AVE $>0.5)$ Discriminant validity 
Jena, S. K. and Ghadge, A. (2021), An integrated supply chain - human resource management approach for improved supply chain performance, International Journal of Logistics Management

(DOI: 10.1108/IJLM-03-2020-0151).

- Multicollinearity: Tolerance value $>0.7$

Structural equation modelling

CFI $>0.9$

IFI $>0.9$

RMSEA $<0.08$ 